\title{
Martial arts teaching present situation and countermeasure research in colleges and universities
}

\author{
Bichuan Liu ${ }^{1, a}$ and Jiahua Dü ${ }^{2, b}$ \\ ${ }^{1}$ PE Department of Jiangxi University of Traditional Chinese Medicine, Nanchang City, 330004 \\ China \\ ${ }^{2}$ School of physical Education and Education Science, Nanchang University, Nanchang City, \\ 330004 China

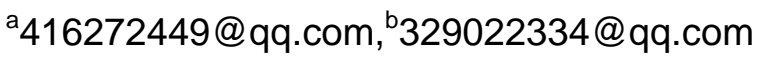

Keywords: The Status Quo; Teaching; Advice

\begin{abstract}
Through consulting relevant literature, adopts the method of literature review, interview method, field survey method, questionnaire method, in-depth local colleges investigation of martial arts teaching in colleges and universities, expounds the role and status of the martial arts class in colleges of our country, analyzes the current status of college wushu teaching, and discussion and analysis on current situation of wushu teaching, put forward advice on how to teach it martial arts.
\end{abstract}

\section{Introduction}

Through martial culture, martial arts can strengthen physical health, also can to defense the enemy attack.Kung fu people to "stop the invasion" as the technical guidance, leading the aspirant into understanding between human and nature, the objective law of social traditional indoctrination (martial culture), is the human material civilization of guidance and protection.

Martial arts, with the strength of the ground war, maintain peace.As descendants of the Chinese nation's survival skills, Chinese traditional martial arts with the development of Chinese history and civilization, gone through a journey of thousands of years of wind and rain, become a soul for the national survival and development, and children carry the genetic makeup of spirit, check in.Wu Shu is to have and maintain its own security and power.We practice martial arts, is let us from body to heart, and was promoted by the soul and spirit and full of sense of security, robust, god has since enron wins.This is my family dynasties precipitation and become, requiem keep spirit.Martial arts concept is the basic foundation of study martial arts people know.In the long historical process, in different periods of different expression of the concept of martial arts, its connotation and denotation is with the development of social history and the martial arts of their own development.

Martial arts in the process of historical development has different titles, such as the spring and autumn period and the warring states period "art," he said of the han dynasty called "martial arts", called "martial arts", at the beginning of the qing dynasty during the period of the republic of China according to "martial arts", after the founding of new China officially named "martial arts".

With respect to its content and form, and recorded in the ancient martial arts dance practice routine movement in the form of "sparring" "make good" "gun" "dance" dance, "' spear" sword dance "the practice of the individual and collective" sword dance "and so on, and" gun "" jian" brand such as double prepared.To fight against a form of exercise has "sacral Angle" "beat" "sumo" "fencing" "a good" "spear guns", etc.Coming from the old s compared with today's martial arts, martial arts of the covers the content and form of the existence of many differences, but the essential attribute is consistent, coherent.Historically, early humans in survival competition, hunting, and war and martial arts skills in the form of the early technology form homologous isomorphism, even in a certain period synthesize interweave, however both with the change of history, martial arts development up to now, the function of sports increasingly significant, and belongs to the category of sports, and its content, form and means of TiYuHua features more obvious, so the concept of modern martial artscan be summarized as:Martial arts is the art as the main content, pay attention to, in the form of routines and fighting for the sport, both inside and 
outside and repair of the Chinese traditional sports

\section{Organization of the Text}

The position and function of martial arts teaching in colleges and universities.Martial arts is the art of action as the main content, in the form of routines, fighting, achievement method for sports, pay attention to the Chinese traditional sports of internal and external and repairing.

With the development of The Times, its fields has been involved in education, literature and art, etc.It requires practitioners not only has a certain body quality and movement skills, but also requires a certain culture, a cable.Through wushu practice, enhance the function of each organ of human body oneself, system, improved the fast pace of today's information society, people efficient ability to adapt.

Martial arts in the pursuit of form, gesture, motion, especially pay attention to inside and outside the oneness, xingshenjianbei.In routine practice of technical requirements of the inner vigor closely integrated with external bodies, do hand to eye to form break even meaning, makes sense, breathing and coordinated actions.

Martial arts can strengthen the key body, improve body muscle strength and the extension, improve the extent of joint movement, effectively develop flexibility.Some martial arts, such as taijiquan boxing (or shadow, for the treatment of various chronic diseases and regulating environmental balance in the human body has a good health care function.

Martial arts except with the body's own fitness, self-defense, medical treatment and health care efficacy, but also has entertainment, recreation, social effect, such as performance, social play a dual role of physical fitness and edify sentiment.

Martial arts have the extremely important position in the martial arts in university, through the practice martial arts, improve the human cultural quality and moral standards, and promote the human progress and civilization, and promote the normal development of the college students' body and cultivate the correct posture, shaped into shape, to glow the youth vigor, enhanced physique, improve the ability of prevention and treatment of disease.

By performance, promote the normal communication between people and between universities and friendship, expand the scope of university students' social.To carry forward the national art and culture, and thus the martial arts has become an indispensable teaching course.

\section{Martial arts teaching present situation analysis}

At present the most various types of martial arts in physical education in colleges and universities listed in the syllabus, not only provides the certain teaching validity, and formulate the specific evaluation criteria.Teaching content mainly include: the primary long fist, the primary sword, Taichi, program, paper, etc.Practise achievement method: 18, eight period of jin and other YangShengGong.Some colleges and universities also opened yenu, combined with regional characteristics of martial, sanda class as well as the health care keeping in good health, but there are also some weak links.

\subsection{Different teaching material contents, lack of theoretical teaching}

Different teaching material contents, lack of theory teaching in colleges and universities to carry out different martial arts class the teaching material content, there is imbalance

Status, about a third of the colleges and universities adopt provinces compile for universal use special materials, a third of the comprehensive application of colleges and universities sports teaching material, and one third of the universities adopt handout or in a state of no teaching materials.According to some universities reflect, skill and theory of the phenomenon is still serious.

Due to the lack of some colleges and universities teaching material, teaching theory of void content, thus to further study on the martial arts from practice and theory combining with study, influence the teaching quality, cannot make students from scientific theory to choose suitable for the actual project needed for our physical exercise and keeping in good health, promote health of 
body and mind.

\subsection{Teaching content choice is narrow}

The teaching content choice is narrow, lack of attraction most of the colleges and universities to carry out the martial arts teaching content, usually on primary long fist, green In three way long fist, this paper primary and taichi sword, for the teaching program, and traditional health care keeping in good health and guidance techniques are mostly limited to medical colleges, only a handful of colleges and universities on the basis of the region characteristic to develop all kinds of traditional sports project.

\subsection{Teaching method is old}

Teaching method is old, lack of scientific method the martial arts teaching tradition that involves one thousand theory and law, at present a lot Martial arts teaching in colleges and universities only focus on the teachers "teaching", "student learning" as the main form of the traditional teaching implementation of teaching, method of the single, aging of dharma, and the lack of using the modern sports teaching methods and the best combination of traditional teaching methods to arouse the students' interest in learning and expanding knowledge.

\section{Suggestions,colleges and universities to carry out martial arts class}

\subsection{The martial arts choreography}

Martial arts as one of an excellent national cultural heritage in our country, in our country.National culture occupies an important position in the development, and deep in our countryMass base. After thousands of years of development, constantly enrich its content and factions, fist. There are many different kinds of instruments and can be used as the content of the martial arts performance is also rich and project. But martial arts originally appeared on the stage, in the form of performance choreography is very single, no subject and the plot and content is given priority to with individual routines and prepared, only stage, tao, clothing and so on all is very simple. The performers simply to wushu.To the audience, the performance form is too simple, not easy for a long time to attract the audience.

Martial arts performance after made great adjustment in the choreography, melting in the martial arts performance into the subject and the plot, especially zo century $90 \mathrm{~s}$ martial arts choreography and tables play in the population and scale performance and quality has the very big breakthrough.Martial arts choreography plait martial arts is a very complicated work, its basic requirement is to have a new idea, has a unique style, makes every effort to action stretch generous, consistent, and accurate position arranged neatly, harmonious and unified, must have certain sports load, can play the role of physical fitness.Even at the same time conform to the requirements of the regulations, rules, comparable and athletics. Teachers should master the martial arts of the latest information, to know martial arts development.

Through a variety of video and relevant materials and various forms of communication activities (e.g., visit, study, game), understand the martial arts development level and trend at home and abroad and on the new action, composite structure, rules, requirements, etc.Collecting a large number of related martial arts movement and material.I.e. the various types of martial arts movements, and various types of art form, the accumulation, for the plait.

The important thing is in the process of the specific programs, according to the current development trend of domestic and foreign martial arts, from the aspects of action and style, pay special attention to determine their own characteristics and style.

For example, due to the low starting point of some college students in wushu, poor foundation.Each step depends on the teacher support, so can't imitate those with international level of "high" "hard" "new", "fast" the high level of skill moves, also cannot copy that only certain domestic sports level of the athletes' techniques, and can only according to the specific circumstances of students, learn other people's short and pithy flexible action, bold and lenovo, innovation.

\subsection{I deological education}


To strengthen students' ideological education, give full play to the role the backbone of sports teachers undertake to the student ideological education, set up the correct health perspectives, and sports Concept, strengthen the health consciousness, help students build up confidence, so that they develop good exercise habits, adhere to the regular physical exercise, enhanced physique.Sports backbone role into full play, in addition to the athletics member of committee, the selection of superior grades 2, 3, organized, strong sense of responsibility of the student cadre to assist helps the mutual method, namely students in pairs, help each other mutual comparison, corrective and improvement actions.Give full play to the advantages of political theory, and improve the students' ideological and political quality.According to fully embody the requirements of the latest achievements in contemporary marxist, comprehensively strengthen subject construction of ideological and political theory course, course construction, construction of teaching material and teacher team construction, and further promote the deng xiaoping and "three represents" important thought into the teaching materials, into the classroom, into the college students' minds work.To contact the reform and opening up and socialist modernization construction practice, contact with the ideological reality of the college students, to impart knowledgeCombined with ideological education, combine teaching and special education system, combine theory armed and practice education, to reform theteaching contents, improving teaching.

\subsection{The teacher's leading role}

Give full play to teachers' leading role of the teacher's words and deeds will directly affect the students' learning interest and motivation.Teachers to discipline, a teacher by worthy example, fair and accurate, demonstration action specification, graceful, fluent in mandarin, rich teaching contents, various forms, continuously improve the teaching method, using a variety of teaching methods, constantly attract the attention of students, arouse the enthusiasm of students, make students in a good learning environment.

In the process of teaching teachers should pay attention to the basic skills and basic movements, the basic skills and basic movements not only can make students get more comprehensive exercise, body itself can also quickly development of wushu sports special physical quality, to master and improve the level of routine technology to lay a good foundation.Teaching difficulty and complicated movements, the first difficulty is the teaching emphasis, best arrangement before each routine teaching, teaching students the most energetic.In the process of teaching teachers should pay attention to the basic skills and basic movements, the basic skills and basic movements not only can make students get more comprehensive exercise, Already so could pave the way for the routine teaching, saving teaching time, and can guarantee the difficulty complex action of many times before and after repeated practice and action link integrity.Finally around the key action section teaching, where an action is divided into several sections or some coherent combination action taking teaching routines.

Section to pay attention to the action of continuity and inner link.And pay attention to the change of demonstration position of unfavorable and overmuch.Teachers should take action when demonstrations on vivid, image, intuitive, and correctly, at the same time, also need to take action of skilled and beautiful degree, of course, need more teachers with some acting skills.Using the method, means, measures, venues andequipment and so on should be reasonable arrangements, and pay attention to the scientific nature and rationality, means diversity and interesting, and 1 from set out actually, according to their aptitude, as well as considering the demands of complete generality, and should consider the motives of personality development, in order to promote the all-round development of students body and mind, but also pay attention to cultivate students' enthusiasm to learn martial arts. 


\section{Summary}

Looking forward to the new century, martial arts teaching in colleges and universities hasa broad prospect and the future.With the progress of modern society and cultural development. College sports to inherit and carry forward, provide a good spread of martial arts teaching, and scientific principle and the method to guide the popularity of traditional ethnic sports and improve.

Let this special form of martial arts and cultural heritage, through the refining and development of higher learning, for students to master and apply, spread to the society, is quite strong, remain plentiful energy, make contributions to the socialist modernization drive.

\section{References}

[1] Yan jun. Sports teaching psychology [M]. China press, 1993

[2] Cai zhong-lin . Martial arts [M]. Beijing: higher education press, 1995

[3] Pan shu. Education psychology [M]. Beijing: people's education press, 1980 